\title{
Correction to: Nutritional status and food intake in pediatric patients with inflammatory bowel disease at diagnosis significantly differs from healthy controls
}

\author{
Sara Sila $^{1} \cdot$ Ivana Trivić $^{1} \cdot$ Ana Močić Pavić ${ }^{1} \cdot$ Tena Niseteo $^{1} \cdot$ Sanja Kolaček $^{1,2} \cdot$ Iva Hojsak $^{1,2,3}$ (D) \\ Published online: 23 January 2020 \\ (C) Springer-Verlag GmbH Germany, part of Springer Nature 2020
}

\section{Correction to: European Journal of Pediatrics}

(2019) 178:1519-1527

https://doi.org/10.1007/s00431-019-03443-3

The authors of the published original version of the above article wanted to correct the text below in the Abstract section.

The text originally read "Mean energy intake was significantly lower in healthy controls compared to patients with ulcerative colitis, but not in patients with Crohn's disease." should instead be read, "Mean energy intake was significantly higher in healthy controls compared to patients with ulcerative colitis, but not in patients with Crohn's disease". [Bold text used to highlight problem area]

The original article remain unchanged.

Publisher's note Springer Nature remains neutral with regard to jurisdictional claims in published maps and institutional affiliations.

The online version of the original article can be found at https://doi.org/10. 1007/s00431-019-03443-3

Iva Hojsak

ivahojsak@gmail.com

Sara Sila

sara.sila0810@gmail.com

Ivana Trivić

ivana.trivic.0@gmail.com

Ana Močić Pavić

amocicpavic@gmail.com

Tena Niseteo

tniseteo@gmail.com
Sanja Kolaček

sanja.kolacek@gmail.com

Referral center for Pediatric Gastroenterology and Nutrition, Children's Hospital Zagreb, Klaićeva 16, 10000 Zagreb, Croatia

2 School of Medicine, University of Zagreb, Zagreb, Croatia

3 School of Medicine Osijek, University J.J. Strossmayer, Osijek, Croatia 